Running head: ETHICAL DILEMMAS COVERING TRAUMA

\title{
Journalism on the spot: Ethical dilemmas when covering trauma and the implications for journalism education
}

\author{
Elyse Amend \\ MA, Journalism Studies, Department of Journalism \\ Linda Kay \\ Associate Professor, Department of Journalism \\ Rosemary C. Reilly \\ Associate Professor, Department of Applied Human Sciences \\ Concordia University \\ Montréal, Québec, Canada
}

Correspondence should be addressed to Linda Kay, Concordia University, Department of

Journalism, 7141 Sherbrooke St. West, CJ-3.245, Montreal, Quebec, Canada H4B 1R6

Email: $\underline{\text { indamkay@gmail.com }}$

\section{Acknowledgements}

This research was supported by a grant from the Social Sciences and Humanities Research

Council, Ottawa, Canada. Parts of this paper were presented at the 1st Canadian Journalism

Forum on Violence and Trauma, London, ON and at the International Conference of Journalism Research in the Public Interest in Zurich. 


\begin{abstract}
When covering traumatic events, novice journalists frequently face situations they are rarely prepared to resolve. This paper highlights ethical dilemmas faced by journalists, who participated in a focus group exploring the news media's trauma coverage. Major themes included: professional obligations versus ethical responsibilities; journalists' perceived status and roles; permissible harms, and inexperience. Instructional classroom simulations based on experiential learning theory can bridge the gap between the theory of ethical trauma reporting and realities journalists face when covering events that are often chaotic and unpredictable by their very nature. A simulation outline that can be used by journalism instructors is provided.
\end{abstract}

\title{
Keywords
}

ethical dilemmas, media coverage of trauma, journalism education, classroom simulations for trauma coverage 


\section{Journalism on the spot: Ethical dilemmas when covering trauma and the implications for journalism education}

Journalists covering traumatic and violent events must make serious, on-the-spot choices in the field that can represent decisions between two or more "right" moral duties (Kim \& Kelly, 2010). Such ethical dilemmas (e.g. choosing whether to interview victims of violence versus respecting their privacy) often present conflicts between the individual journalist's personal sense of ethics, and the ethical values of the society in which the journalist operates (Kim \& Kelly, 2010; Muller, 2010). Research has shown that a sense of ethics and the navigation of ethical dilemmas in journalism are generally based on the moral standards set by individual reporters themselves (Muller, 2010) and can differ in particular situations and circumstances (Kim \& Kelly, 2010).

This individualized nature of ethical decision-making and lack of consensus on what ethical or unethical behaviour is when covering violence and trauma may be due in part to a gap between classroom approaches and newsroom realities: while ethics has an established place in journalism education (Lambeth, Christians, Fleming, \& Seow, 2004), only a handful of schools have taken a multidisciplinary approach to media ethics, offering courses with practical training (Dufresne, 2004). As Lambeth et al. (2004) observed, "Given that the gap relates to a mutual interest in upholding ethical standards, there would seem to be a real need for wider and more imaginatively designed bridges between journalism educators and practicing journalists in matters of ethics" (p. 252).

This article draws links between the ethical dilemmas journalists face when covering trauma and violence and explores how a journalist's actions are tied to his or her level of training and preparedness. Importantly, it suggests options for improved educational practices. It begins with 
an overview of both the literature on ethical dilemmas faced by journalists covering trauma and violence, and the journalism education and training in these areas. It then turns its attention to the results of a focus group held with seven Canadian journalists who discussed the dilemmas they have faced covering traumatic events in their careers. The article concludes with an outline of a classroom simulation that may be used as a tool to bridge the gap between the theory of ethical trauma reporting and the realities journalists face on the job.

\section{Trauma, Ethics, and Education}

Research has shown novice journalists are most likely to encounter a traumatic event early on in their careers (Dworznik \& Grubb, 2007; Maxson, 2000). However, studies also reveal these journalists often feel unprepared to deal with the emotional and ethical issues related to covering trauma. One study found that one-third of the 400 journalists interviewed either felt not well prepared or not prepared at all to deal with victims of violence or trauma (Beam \& Spratt, 2009). Furthermore, journalists who cover these events receive little guidance from within the newsroom (Duncan \& Newton, 2010). The literature has identified a number of problems that can arise when ill-equipped journalists are faced with covering a traumatic event: a lack of sensitivity when dealing with victims (Dufresne, 2004; Maxson, 2000) and other actions that can impede recovery or cause retraumatization (Simpson \& Coté, 2006; Sykes, Embelton, Green, Hippocrates, \& Richards, 2003); serious ethical violations such as misrepresentation, lying, and being unnecessarily intrusive (Maxson, 2000; Muller, 2010; Walsh-Childers, Lewis, \& Neely, 2011); and an inability to move coverage of trauma and violence beyond the events themselves toward truly powerful and meaningful stories (Fullerton \& Patterson, 2006; Maxson, 2000).

These are important issues since journalistic reporting on violence and trauma can have serious effects on journalists, their audiences, and the victims. For example, based on interviews 
with survivors of the 2007 Virginia Tech shootings, Walsh-Childers et al. (2011) found that, although some cathartic effects were reported by those who dealt with compassionate journalists, victims often conveyed a sense of invasion and journalist insensitivity.

\section{Ethics Education}

In order to mitigate the negative effects news reports of trauma and violence can have, some scholars have called for changes in the way journalism is taught and practiced, such as reporting on crime in terms of patterns rather than personal motivations (Dorfman, Thorson, \& Stevens, 2001), approaching stories on violence and trauma with goals of public interest, responsibility, reconciliation, and social justice, and assuming an ethic of care (Patterson \& Fullerton, 2006). Additionally, organizations such as the Society of Professional Journalists (SPJ) and the DART Center offer guidance on how journalists should deal with victims of trauma and violence, by promoting the notion of "minimizing harm," with suggestions such as: treating victims with dignity and respect; interviewing empathetically and sensitively; balancing what the public needs to know versus providing unnecessary details; and recognizing that the coverage of trauma will have an impact on the victim (Hight \& Smyth, 2003; SPJ, 1996).

However, journalists do not always put such principles into practice, which can result in the negative effects highlighted earlier. Research has suggested this may be because media ethics courses do not adequately train new journalists for dilemmas they may face on the job. Despite calls from journalism students, teachers, and researchers for improved and increased training (Dworznik \& Grubb, 2007; Joseph, 2011; Maxson, 2000), to date only a handful of schools offer media ethics courses with a practical or trauma training component, which might include inviting trauma victims to speak to students about their experiences; learning strategies to cope with stress and secondary trauma; and mock interviews with actors posing as victims (Dufresne, 2004; 
Dworznik \& Grubb, 2007; Maxson, 2000; Rentschler, 2010). The literature also suggests methods for teaching best practices in ethical trauma reporting in journalism schools or courses are in need of elaboration. As Joseph (2011) writes

I believe the crucial role of journalism education in helping young journalists develop an appropriate 'moral compass' at this point should be a mandatory unit of tertiary learning. Working more explicitly with concepts of empathy and compassion may help position the journalist and allow him or her to make those voluntary ethical decisions about their subjects in a less detached fashion. (p. 23)

\section{Use of Simulations}

There is evidence classroom simulations of crises are beneficial in training and preparing new professionals for dilemmas they will encounter in the field (Veil, 2010). While such training methods are not widely used, classroom simulations have the potential to better prepare novice journalists and help them establish ethical norms and practices for reporting on trauma and violence. Simulations in the classroom make course material relevant, stimulating and vivid, and spark student interest (Hess, 1999). Based on the principles of experiential learning (Kolb \& Kolb, 2005), simulations of traumatic events can not only permit students to apply their theoretical knowledge, but develop the necessary interaction skills that characterize sensitive trauma reporting. They reveal the subtleties of empathetic human social interaction and are very effective in building communication skills (Koponen, Pyörälä \& Isotalus, 2010). Simulations also allow students to engage in behavior that approximates a realistic situation, to act and react to the situation as a journalist might, while at the same time permitting the instructor to observe, coach, and ultimately, comment. Even single-session simulations have shown to considerably impact student learning (Baranowski, 2006). As well, simulations create spaces for collective 
professional reflective practice, both reflection-in-action and reflection-on-action (Schön, 1983), which can positively contribute to journalists' professional growth (Author B et al., 2011). Significantly, studies show simulations are one of the most effective ways to ensure information is retained (Shellman \& Turan, 2006).

Supported by the findings of a focus group discussion with seven Canadian journalists, this paper will argue classroom trauma simulations are an efficient way to educate and prepare journalism students for the situations and ethical dilemmas they will encounter in their careers, and we propose ways to effectively implement such forms of training.

\section{Experiences from the Field}

After conducting an inquiry into the impact of media coverage on a small rural community (Author B et al., 2010), we wanted to explore with journalists their beliefs, experiences, and recommendations when it comes to covering traumatic events. We were particularly interested in knowing what ethical dilemmas they currently faced in the field.

\section{Method}

We gathered data by using a focus group format, an interactive group research method capturing real-life data in a social environment (Morgan, 1997). This, we thought, was the best setting to illuminate the unique ethical dilemmas journalists faced while covering trauma, and an ideal way to highlight collective conceptions about professional ethical boundaries. The strength of this method is that it: (1) elicits perceptions, feelings, attitudes, and ideas concerning current ethical dilemmas; (2) gains the assistance of journalists in defining the ethical boundaries and responsibilities towards sources and to the public; (3) provides a dynamic source of data directly from participants; and (4) stimulates the participants to elaborate beyond the usual limits of expression constrained by individual interpretation (Vaughn, Schumm \& Sinagub, 1996). 
Groups tend to have a synergistic effect, generating more associations and insights among the participants (Morgan, 1997). They are particularly useful when the purpose is to explore concepts, sample opinion, and identify trends, and take advantage of the power of collective and collaborative thinking and problem solving (Krueger \& Casey, 2000).

Eight Canadian journalists living in a major city in central Canada (five men and three women representing radio, print, and television news outlets) accepted the invitation to participate in the focus group. Due to a national breaking story, one male journalist had to cancel at the last minute. Participants were selected because they were currently involved in the news industry and represented a range of experience, from three to thirty years. There was no expectation these journalists be statistically representative; rather they were viewed as a panel of expert professionals working in the field, and were consulted in order to articulate knowledge and practices currently in use. The moderator, (Author B), was also a veteran journalist. The session lasted approximately two hours, and was recorded to accurately capture the conversation and social interaction. In order to set the norm of interactive exchange where participants were free to talk with other group members, a round robin format was not used. Instead, participants were instructed to allow the conversation to flow, as a more spontaneous and dialogical approach (Isaacs, 1999) was deemed most useful.

\section{Data Transformation and Analysis}

The focus group recording was transcribed, and the text subjected to analysis. We created a general framework for processing the data, and used it consistently throughout the analysis (Strauss \& Corbin, 1998). We provisionally categorized the text into similar inductively derived thematic concerns (Aronson, 1994; Ely, Vinz, Downing, \& Anzul, 1997). A thematic concern captured something salient about the data with regards to the research objective (identification of 
ethical dilemmas), and represented some level of meaning within the data at a semantic level (Braun \& Clarke, 2006). We formed propositional statements (i.e. a definition of the category) to characterize the key themes, and developed rules for categorizing the data (i.e. what was included or excluded) to keep each theme internally consistent. The "keyness" of a theme was determined by examining whether it captured something important in relation to the overall research focus. We then gave each one a title that attempted to capture the essence of the theme. We proceeded with this process until the following criteria were fulfilled: exhaustion of data sources, saturation of themes, emergence of regularities, and overextension (Lincoln \& Guba, 1985).

\section{Findings}

Four key themes surrounding ethical dilemmas in trauma reporting emerged: (1) professional obligation versus ethical responsibilities; (2) journalists' perceived roles; (3) permissible harms; and (4) inexperience.

Professional obligations versus ethical responsibilities. This theme reflected the personal tension between journalistic job obligations and ethical responsibilities as a member of society. All seven journalists had experienced such dilemmas at least once in their careers when covering trauma, most commonly having to choose between "getting" the story by being intrusive or using people who may be in shock and respecting these peoples' right to privacy and dignity. As Archer noted, "I just found personally that I was having real trouble differentiating between the wanting to be the pop psychologist and telling them to stop talking to me, and wanting... needing to be the journalist and getting the story done."

Certain pressures that are part of daily journalistic routines, such as deadlines, tracking down sources for stories, and demands from the editorial desk, all compounded the decision-making 
process. When faced with such dilemmas, journalists do not often have the luxury of time to weigh the morality of all options. Katy observed, "You don't have a lot of time to think and you don't have a lot of choice, I don't think. Because the next deadline is maybe, you know, 15 minutes away."

Participants reflected these realities of the job, which especially affected novice journalists with little experience in the field who may act unethically at times due to pressures caused by competition with other journalists and news outlets, and their own career advancement. Ryan remarked, "I think this problem that we're discussing here is especially compounded for new journalists, who feel the pressure to perform, produce, beat the competition, win at all costs, whatever ... they feel vulnerable, or they're just trying to get ahead."

The weight of ethical dilemmas between job obligations and ethical responsibilities caused one veteran journalist, Archer, to question the processes and true goals of trauma and violence reporting. "I just found that my ability to convince myself that I was actually doing something of good for the community and why I had gone into journalism, to educate and try and help people - I couldn't reconcile that anymore."

While not all participants expressed such journalistic identity crises as Archer, the group members did articulate that navigating ethical dilemmas between job obligations and societal responsibilities was most often a personal matter to be sorted out on one's own.

Amelia: At the end of the day, I have to look myself in the mirror and to me, that's very important. I won't sacrifice my integrity for, you know, being the first to get the 
story. I definitely think that [getting the story] is important, but I think there are better ways to do it.

Journalists' perceived role. A considerable portion of the group's discussion turned toward how participants defined their roles as journalists when reporting on traumatic events, for example "storyteller," "analyst," "historian," and "witness." The individual journalist's perceived role influenced how they navigated ethical dilemmas, such as those between job and societal responsibilities described in the previous section.

Maggie: People are interested in what happens to people in people's lives and I think it's our role to tell those stories so that, maybe, at the end of the day, it either changes something or improves something. Or if nothing else, it just makes people feel that we have to do something to improve our society.

William: We're here to report history, right? I mean, how do you justify what you do? Because there's this nagging suspicion that what you're doing is sometimes an invasion of privacy and it's gratuitous and exploitive and sensationalistic.

Participants expressed that journalists adapt their roles to the particular situation they find themselves in, thus causing ethical values to become flexible. For example, if a journalist is pressed for time in the field, he or she may take on the role of "witness" and just report the facts of a traumatic or violent event. Once that same reporter has more time and/or is able to reflect on the event, they may take on the role of "analyst" and frame the story in terms of larger issues. The following illustrates this flexibility: 
Maggie: You question what you're doing. I think that's normal and I think it's healthy. But I don't think we always have to be doing something, for lack of a better word, good or helpful. I think it's the human condition and that's what we write about. Like, what is going on in the world and sometimes it's not pretty...

In terms of intruding on victims' privacy or exploiting a traumatic event for the purpose of producing a news story, participants generally agreed their journalistic role, or "obligation" as William described it, of "raising awareness" about bigger issues through their stories made this necessary at times, so long as journalists take a constructive rather than exploitative approach to their work. Archer took this sentiment a bit further, asserting journalists are also "part of the resolutions." In fact, participants viewed the actions associated with such perceived roles as a fundamental part of journalism itself.

Archer: There are stories that we have to tell, even if people tell us they don't want to read about it. Our role is to shine light and to say, "Look, you may not want to hear about this and maybe we don't have to do this five days of the week or have our whole paper or broadcast filled with this, but here are some things in your community that you do need to know about." So, I mean, if we give up that part of our craft, why are we in journalism?

Permissible harms. Discussions about navigating ethical dilemmas ultimately resulted in talk about "permissible harms" or those actions that would normally be considered unethical but are deemed allowable by journalists working in the field in order to fulfill their perceived journalistic obligations. Interestingly, however, while all participants agreed some harms are necessary when reporting on traumatic and 
violent events, there was little consensus on exactly what harms were "permissible" and which ones were not. For example, while some participants stated is was acceptable to interview victims shortly after a traumatic event if they agreed to speak to the journalist, others thought this might not be so black and white, as victims might agree to be interviewed while they are in shock but regret it or feel used later.

Julio: I think it's sometimes surprising... how open people are... you're going to make a call to somebody who's grieving 'cause they've lost somebody tragically... You're just surprised how open they can be. Sometimes they don't even visibly... it doesn't even seem to affect them...

Maggie: Because they're in shock...

Julio: Sometimes, I guess it's because they're in shock but-

Maggie: It's the best time to get them.

Archer: Yes, the only time to get them.

Maggie: I hate to say it but-

Archer: It's true.

Ryan: Or they just expect it's a normal course of events, when you lost a loved one in the fire, that the satellite trucks show up at your house because you've seen that so many times...

Julio: Maybe it's not unfair if they're in shock, I don't know. I've felt that way at least, where maybe someone was in shock or maybe they were talking to journalists, 
but they weren't expecting it to be everywhere. Maybe after they regret it and they see it, you know, big newspaper front page.

The above exchange demonstrates not only that certain potentially harmful actions are viewed as permissible in violence and trauma reporting, but also shows the highly individualized nature in which ethics are applied and decisions negotiated, balanced, and perhaps rationalized.

There was also some discussion focused on different categories of harm and, as the following illustrates, the internal negotiation that happens in an attempt to distinguish what is permissible and what is not.

Katy: When you think about the harm that we do, I mean, people feeling alienated from their community or feeling that we were intruding on their privacy. Nobody dies from those things, you know? I'm sort of aware that these things are harmful or people are unhappy about them. But I don't carry a huge amount of guilt about this.

A related trend emerged surrounding how journalists earlier on in their careers and veteran reporters navigated these types of dilemmas and where one should draw an ethical line when reporting on violence and trauma. Specifically, veteran reporters such as Katy did not feel as "guilty" when causing harm deemed permissible on the job, while another veteran reporter, Maggie, stated she did not have a problem "bending the truth" at times (in this case, not stating she was a journalist when asked) so long as it does not cause any direct harm or grief for the victims or victims' families. Participants, like Julio who were in the early parts of their careers, expressed some discomfort with such notions, and seemed to question the value of doing any type of harm. "But, then you debate: Is it worth it? You know, is that worth sort of breaking that trust versus the competition?" 
Although these differences between more novice and veteran reporters emerged in the focus group, these discrepancies were tempered by recurring discussion on the fact that definition of "permissible harm" was generally based on each "individual journalist's code of ethics," as William described and others elaborated on:

Ryan: I just think it comes down to the minutia of how we all do our job when we get there. And I've crossed the line too. You know when you do it. You may have had to do it, or you may regret it. But, I think it just comes down to the individual behavior.

Inexperience. When questions about education and training came up, all participants had essentially the same reaction: they had received little or no training on how to deal with reporting on traumatic and violent events and the associated ethical dilemmas. Archer indicated this is of particular concern for rookie reporters. "I would be willing to bet a fair amount of money, that many... that most journalism students leave school and then on their first real trauma experience are, like, 'Whoa! No one ever prepared me for this...",

Journalists, like Amelia, used experience in the field, and not prior education or training, to inform their decisions and behavior. "One thing that I remember, it was very, very chaotic and as a rookie journalist, being thrown into that kind of situation, I was so overwhelmed. But it was a good learning experience too, for future traumas."

Some participants noted that it can be difficult to teach young journalists how to deal with these situations, as journalism is "not applied mathematics" with a manual that lines out what steps to take in a given situation, as Archer put it. Another participant noted while current methods of introducing concepts of trauma and violence in journalism school courses, such as 
professors relating their own experiences or having presentations from trauma and violence professionals, might be valuable to an extent, they are inadequate for truly preparing young journalists for what they will eventually face on the job.

Amelia: It's a learning process. Once you get out there, that's where you're going to learn. I think it's very hard to... I think it's great to touch base and talk about it in class with the students. But, it's not the same as being there in that situation.

Despite these difficulties, however, the participants did agree increased training and education could be beneficial in preparing young journalists if it is done more effectively. One participant offered some suggestions for improved practice.

William: I think it would be good to have post-mortems of news coverage following traumatic events and we say, did we cross the line? What could we have done better? I don't know if you can really do this in journalism schools because, how can you simulate a traumatic event in a classroom?

\section{Implications for the Classroom}

Our focus group discussion with Canadian journalists revealed four major themes: (1) compounded by job demands such as deadlines and editorial pressures, journalists regularly face dilemmas between their job responsibilities and ethical obligations as members of society, and navigate these based on their individual "moral compasses" (Muller, 2010); (2) journalists' perceived roles, which are flexible and adapted to particular situations, influence how they navigate ethical dilemmas when covering trauma and violence and rationalize any harms they may cause; (3) journalists agree causing "permissible harm" is inevitable in journalistic practice, however there is little consensus on where the line between "permissible" and "impermissible" 
should be drawn; (4) journalists receive little or no training on how to deal with ethical dilemmas when reporting on trauma and violence and agree that, while it may be difficult to translate such training into a classroom setting, more education would be beneficial. These findings are largely in line with the wider literature that indicates journalists navigate ethical dilemmas based on their individual morals and interpretations (Kim \& Kelly, 2010; Muller, 2010). These discrepancies may be a result of the lack of training novice journalists receive in these areas, thus leading to general inexperience and inability to make ethical decisions when faced with trauma and violence in the field (Beam \& Spratt, 2009; Dworznik \& Grubb, 2007; Maxson, 2000). As inexperienced journalists can cause a number of harms, such as not being able to produce meaningful stories (Fullerton \& Patterson, 2006; Maxson, 2000), insensitivity when dealing with victims (Dufresne, 2004; Maxson, 2000;), and other serious ethical violations (Maxson, 2000; Muller, 2010; Walsh-Childers et al., 2011), there is a vital need to improve training for novice journalists in order to counter these problems (Joseph, 2011). We believe using classroom simulations may be an effective tool in achieving this, and we offer guidelines on simulation design and an outline of a classroom exercise.

\section{Use of Simulations to Teach Ethical Trauma Reporting Practices}

As previously noted, simulations can be used to bridge the gap between the theory of ethical trauma reporting and the complex realities journalists will face when working in circumstances that are often chaotic and unpredictable. Similar to the way physical science students learn scientific principles from laboratory experiments, simulations allow students to learn from firsthand experience in a safe and contained environment. As Jones (1995) explained, "It is the environment that is simulated... but the behavior is real" (p. 7). 
As trauma and tragedies can be volatile events, classroom simulations are one way to duplicate an environment that cannot be simply studied and observed in real time, but that a journalist might well encounter in the field (Veil, 2010). Interestingly, although instructors design a simulation carefully, it can also have a life of its own, dependent upon the unique reactions and previous experiences of student participants. Thus, a simulation has an unpredictable element, mirroring the nature of a real-life traumatic event (Shellman \& Turan, 2006).

A well-designed simulation is more than just interactions between participants. They are believable recreations of real events, involving authentic situations, choices, and outcomes that focus on a key learning dynamic. Generally, simulations are divided into three phases: (1) preparation; (2) interaction; and (3) debriefing (Asal \& Blake, 2006).

The preparation phase is a time when instructors can provide the necessary conceptual material to students to help inform their behavior during the simulation. This might include covering the historical evolution of journalistic practice regarding trauma reporting, discussing how to treat victims with dignity and respect, and some principles regarding sensitive interviewing. As well, this is a time when students are introduced to their roles, and may spend time on their characters' "back stories." A successful simulation is one in which students are not only drawing upon their own experience and values, but are also faithful to the characters they are portraying. The interaction phase is the actual simulation. This is where the students have the opportunity to put their knowledge into action and hone their trauma reporting skills. The final phase, debriefing, is a guided group discussion that draws out participants' feelings, thoughts, and reactions, and allows the instructor to highlight what has been learnt.

Certain principles can assist the educator in building effective simulations: 
- Teaching goals must be clearly defined. In designing a trauma simulation, the educator will likely have multiple aims. These can range from preparing students to keep a cool head under pressure to coaching them to ask questions in a sensitive and empathetic manner. At the same time, successful simulations contain unscripted elements. This means the scenario can go in a direction that is unexpected and raises issues even the instructor may not have initially anticipated. Successful simulations have a dynamic that differs with every class. The path it takes will vary depending on the actions and reactions of the participants. This, in turn, presents dilemmas and raises questions that are unique to that scenario.

- The educator must construct the simulation so it is a meaningful depiction of an authentic trauma situation that could easily occur in the students' immediate vicinity. Props are helpful, but they should be kept simple and unobtrusive. It's the content of the scenario and the interactions that emerge that matter, not the scenery.

- Simulations should engage the entire group. Not everyone can partake in the role-play (nor should they, since the role of observer is key), but all students must participate in some fashion in order to keep everyone connected to the event.

- Simulations should elicit an emotional reaction of some sort. The instructor, in sketching out the simulation for the students, must paint a compelling picture of the traumatic situation without providing too many details, since student participants will fill these in. But the gravity and traumatic dimension of the simulated event should be stressed. However, the instructor must keep in mind that simulations can be psychologically powerful, and therefore strive not to build in elements that are emotionally manipulative and beyond the age and developmental stage of the students (Drake, 2008). 
- Simulations offer students an opportunity to reflect on the trauma reporting experience while it is occurring as well as afterward. "Stop the action," a pause point while remaining in role, may be a useful tool to have students reflect on what they are doing (reflection-in-action), why they are doing it, and what they are learning in the moment (Asal \& Blake, 2006). At the end of the simulation, the instructor must provide ample class time to discuss the implications of the scenario that has just unfolded and create a guided discussion that promotes an examination of what happened, exploring effective and ineffective trauma reporting practices, alternative responses, and the ethical resolution of reporting predicaments (reflection-on-action). In other words, the simulation is just a starting point for conversing about the ethical dilemmas that may have arisen. The conversation that takes place after the scenario is ultimately of greatest value. As well, written reflection assignments can be used to solidify the learning and internalize the practices and values. Without guidance and time for reflection, students may not be able to make the connections between what they have learned in the simulation, and the concepts and principles that have been introduced by the instructor (Asal \& Blake, 2006).

- Lastly, the simulation should be executed at a point in the semester when students are comfortable enough with each other to enact it, yet still have ample time left in the semester to reflect upon it. The exercise then serves as a referent for the remainder of the term; discussion of the lessons learned can extend beyond the confines of one class.

\section{An Example: The Art Gallery Fire}

The following is an example of a simulation that has been used with students in a mandatory introductory class on reporting. Different issues have come up every time the 
simulation has been employed. An art gallery fire was chosen since: (1) fires are often the first traumatic event a young reporter will cover; (2) it holds within it all the real-life drama of authentic, on-the-spot news coverage; and (3) a fire in an art gallery does not necessarily imply loss of life, which, for many students at the introductory level, might be too harsh a scenario to enact.

Description of the event. Students are told a fire is raging at a leading art gallery located on a main artery in the city. They are asked to pretend they are reporters who have been assigned by an editor to take a taxi to the scene immediately and cover the story. Every student is then told to use the time they have in the taxi to write down five questions they believe must be asked at the scene. They are also asked to come up with a list of probable sources to be interviewed at the scene.

Assigned roles within the simulation. After all students have determined their questions and sources, the instructor selects eight students to carry out the simulation by assuming the following roles: police chief, fire captain, ambulance driver, eyewitness, gallery owner, two artists, and finally, journalist (additional roles to consider may be: a resident of an apartment above the gallery or a neighboring businessperson whose store is at risk). A simple prop is handed to them so students can easily identify each role player (for instance, the journalist receives a reporter's notebook, and the eyewitness receives a briefcase). Students are encouraged by the instructor to "get into" their character and imagine how that person would really respond to the traumatic event that is unfolding. Students who are not playing a part will also have to write a story about the traumatic event and are told to take notes as if they were the reporter at the scene. 
The simulation process. The instructor asks the role-playing students to assemble at the front of the classroom where they can be seen by all remaining students, and signals for the reporter to begin asking questions. The instructor then allows the scenario to unfold while the students play out their assigned roles. The students dictate the flow of the scenario without coaching from the instructor unless it is needed. For instance, on one occasion, the "journalist" froze and could not begin the questioning process. This presented an excellent opportunity for the instructor to intervene and briefly talk about the paralyzing fear that could overtake an inexperienced reporter confronted by a traumatic event. By normalizing the situation, and with some coaching, the scenario continued. Usually, however, minimal intervention is required on the part of the instructor while the re-creation unfolds. The simulation ends when the “journalist" signals he/she has no more questions.

Processing the simulation. Following the simulation, students are divided into groups, with role-players placed in each one. Each group is then asked to write the first two paragraphs of the Art Gallery Fire Story for the newspaper's website relying only on information gathered at the scene. Issues that emerge as the students discuss the information they have at hand and attempt to write their stories have included: legal questions about a reporter's rights at the scene; questions about the veracity of eyewitness accounts; questions about using unverified accusations in a news story; and significantly, ethical questions about dealing with the victims of trauma (e.g. when to approach them with questions and when not to; how to ask questions with empathy rather than in an offhand careless manner; and how to handle sensitive information gathered from a victim who may have been in shock). The instructor tells the students that, while hindsight is $20 / 20$, by examining what could have been done better or differently, and by 
discussing issues that are often not discussed in newsrooms, everyone benefits: themselves, their sources, and their media outlet.

\section{Conclusion}

Information is imprinted in a powerful way through the use of simulations in the classroom. One student noted after taking part in the Art Gallery Fire simulation, "I would have to say in all honesty that it was the best two hours of university I've had yet." Such classroom simulations address the same themes that emerged in our focus group with seven Canadian journalists, namely navigating job responsibilities and ethical obligations, defining one's role as a journalist covering violence and trauma, and negotiating which harms are "permissible" and "impermissible." Classroom simulations are also an effective tool in addressing the theorypractice gap in education and training identified in the wider literature, and the feelings of inexperience and unpreparedness expressed by our focus group participants.

By providing students an opportunity to discuss these themes before they encounter trauma or tragedy on the job, a classroom simulation begins the process of examining ethical behavior early on. 


\section{References}

Aronson, J. (1994). A pragmatic view of thematic analysis. The Qualitative Report, 2(1).

Retrieved May 19, 2008 from http://www.nova.edu/ssss/QR/BackIssues/QR2-

$\underline{\text { 1/aronson.html }}$

Asal, V., \& Blake, E. (2006). Creating simulations for political science education. Journal of Political Science Education, 2(1), 1-18.

Author b, Author c, Author a, and others (2011) Details masked for blind review.

Author b, Author c and others (2010). Details masked for blind review.

Baranowski, M. (2006). Single session simulations: The effectiveness of short Congressional simulations in introductory American government classes. Journal of Political Science Education, 2(1), 33-49.

Beam, R., \& Spratt, M. (2009). Managing vulnerability. Journalism Practice, 3(4), 421-438.

Braun, V., \& Clarke, V. (2006). Using thematic analysis in psychology. Qualitative Research in Psychology, 3(2), 77-101.

Dorfman, L., Thorson, E., \& Stevens, J. E. (2001). Reporting on violence: Bringing a public health perspective into the newsroom. Health Education and Behavior, 28(4), 402-419.

Drake, I. (2008). Classroom simulations: Proceed with caution. Teaching Tolerance, 33. Retrieved April 23, 2011 from http://www.tolerance.org/magazine/number-33-spring2008/classroom-simulations-proceed-caution 
Dufresne, M. (2004). Trying times: Schools teach about the effects of covering tragedies - for students and victims. The Quill, 92(2), 27-28.

Duncan, S., \& Newton, J. (2010). How do you feel? Journalism Practice, 4(4), 439-453.

Dworznik, G., \& Grubb, M. (2007). Preparing for the worst: Making a case for trauma training in the journalism classroom. Journalism and Mass Communication Educator, 62(2), 191-204.

Ely, M., Vinz, R., Downing, M., \& Anzul, M. (1997). On writing qualitative research: Living by words. Bristol, PA: Falmer.

Fullerton, R. S., \& Patterson, M. J. (2006). Murder in our midst: Expanding coverage to include care and responsibility. Journal of Mass Media Ethics, 21(4), 304-321.

Hess, F. (1999). Bringing the social sciences alive. Needham, MA: Allyn and Bacon.

Hight, J., \& Smyth, F. (2003). Tragedies and journalists: A guide for more effective coverage. New York: Dart Center for Journalism \& Trauma. Retrieved April 25, 2012 from $\underline{\text { http://dartcenter.org/content/tragedies-journalists-6 }}$

Isaacs, W. (1999). Dialogue and the art of thinking together. New York: Currency.

Jones, K. (1995). Simulations: A handbook for trainers. London: Kogan Page.

Joseph, S. (2011). Recounting traumatic secrets. Journalism Practice, 5(1), 18-33.

Kim, Y. S., \& Kelley, J. D. (2010). Public reactions toward an ethical dilemma faced by photojournalists: Examining the conflict between acting as a dispassionate observer and acting as a "Good Samaritan." Journalism \& Mass Communication Quarterly, 87(1), 2340. 
Kolb, A., \& Kolb, D. (2005). Learning styles and learning spaces: Enhancing experiential learning in higher education. Academy of Management Learning and Education, 4(2), 193-212.

Koponen, J., Pyörälä, E., \& Isotalus, P. (2010). Teaching interpersonal communication competence to medical students through theatre in education. Communication Teacher, 24(4), 211-214.

Krueger, R., \& Casey, M. A. (2000). Focus groups. Thousand Oaks, CA: Sage.

Lambeth, E., Christians, C., Fleming, K., \& Seow, T. L. (2004). Media ethics teaching in century 21: Progress, problems, and challenges. Journalism and Mass Communication Educator, 59(3), 239-258.

Lincoln, Y., \& Guba, E. (1985). Naturalistic inquiry, Beverly Hills, CA: Sage.

Maxson, J. (2000). Training journalism students to deal with trauma: Observing reporters behave like “creeps." Journalism and Mass Communication Educator, 55(1), 79-86.

Morgan, D. (1997). Focus groups as qualitative research. Thousand Oaks, CA: Sage.

Muller, D. (2010). Ethics and trauma: Lesson from media coverage of Black Saturday. The Australian Journal of Rural Health, 18(1), 5-10.

Rentschler, C. A. (2010). Trauma training and the reparative work of journalism. Cultural Studies, 24(4), 447-477.

Schön, D. (1983). The reflective practitioner. New York: Basic Books.

Shellman, S., \& Turan, K. (2006). Do simulations enhance student learning? An empirical evaluation of an IR simulation. Journal of Political Science Education, 2(1), 19-32. 
Simpson, R., \& Coté, W. (2006). Covering violence: A guide to ethical reporting about victims and trauma. New York: Columbia University Press.

Society of Professional Journalists. (1996). SPJ code of ethics. Retrieved April 25, 2012 from http://www.spj.org/pdf/ethicscode.pdf

Strauss, A., \& Corbin, J. (1998). Basics of qualitative research: Techniques and procedures for developing grounded theory. Thousand Oaks, CA: Sage.

Sykes, J., Embelton, G., Green, K., Hippocrates, C., \& Richards, I. (2003). Covering trauma: Suggestions for a more collaborative approach. Australian Journalism Review, 25(2), 7383.

Vaughn, S., Schumm, J., \& Sinagub, J. (1996). Focus group interviews in education and psychology. Thousand Oaks, CA: Sage.

Veil, S. (2010). Using crisis simulations in public relations education. Communication Teacher, $24(2), 58-62$.

Walsh-Childers, K., Lewis, N. P., \& Neely, J. (2011). Listeners, not leeches: What Virginia Tech survivors needed from journalists. Journal of Mass Media Ethics, 26(3), 191-205. 